\title{
Evaluating the Implementation and Effectiveness of a Low-Dose Mindfulness-Based Intervention in a Student Sample: a Randomized Controlled Trial
}

\author{
Constance Karing ${ }^{1}$ (D) Andreas Beelmann ${ }^{1}$ \\ Accepted: 28 February 2021 / Published online: 1 April 2021 \\ (C) The Author(s) 2021
}

\begin{abstract}
Objectives The aim of the current study was to investigate whether a low-dose mindfulness-based intervention had short- and middle-term effects on primary (mindfulness, mental and physical health, self-efficacy) and secondary outcomes (attentional control, body awareness, emotion regulation and nonattachment). Further, the study examined whether participant compliance (course attendance, mindfulness practice at home) and satisfaction improved the change in primary and secondary outcomes.

Methods In a randomized controlled trial, 71 university students were assigned to a mindfulness group $(\mathrm{n}=35)$ or a waitlist group $(n=36)$. The intervention was a 6 -week mindfulness-based training. The outcome variables were measured at pre- and postintervention, and at 2.5 months postintervention.

Results At postintervention and at follow-up, the students in the mindfulness group showed a greater increase over time in mindfulness, self-efficacy, body awareness, and reappraisal than the students in the waitlist control group (Cohen's $\mathrm{d}=0.43-$ 1.06). Although a significant intervention effect on nonattachment was found in the Per Protocol sample at postintervention and at follow-up, this effect was not significant in the Intention-To-Treat sample. Further, satisfaction with the training, course attendance, and the frequency of mindfulness practice at home were associated with positive changes in outcome variables.

Conclusions The findings suggest that a low-dose mindfulness-based intervention can promote mindfulness, self-efficacy, body awareness, and reappraisal in students. The quality of implementation seems to be important for the benefits of a low-dose mindfulness-based training.
\end{abstract}

Keywords Mindfulness intervention $\cdot$ Students $\cdot$ RCT $\cdot$ Implementation quality $\cdot$ Follow-up

Mental and physical health problems are common among university students (Grobe et al., 2018; Grobe \& Steinmann, 2015; Khubchandani et al., 2016). A recent study by Eissler et al. (2020) found that the symptoms of depression and anxiety among students were twice as high as among the general population. Several studies have shown that mental health problems among university students are associated with a higher risk of drop-out, poorer academic achievement, lower self-efficacy, and lower study satisfaction (e.g., Ghaderi \& Rangaiah, 2011; Litmanen et al., 2014; Stallman, 2010).

Constance Karing

constance.karing@uni-jena.de

1 Institute of Psychology, Department of Research Synthesis, Intervention and Evaluation, Friedrich-Schiller-University Jena, Humboldtstr. 26, 07743 Jena, Germany
Thus, prevention strategies that promote healthy coping skills, as well as mental and physical health, are necessary on university campuses (Bai et al., 2020). There is substantial evidence that mindfulness trainings are beneficial and accessible interventions for students' mental health (e.g., Halladay et al., 2019; McConville et al., 2016).

Mindfulness refers to the ability to maintain a moment by moment awareness of our feelings, thoughts, bodily sensations, and surroundings in our environment in a nonjudgmental way (Glomb et al., 2011; Kabat-Zinn, 2003). Various studies have found that trait mindfulness, as a general tendency to be mindful (e.g., Kiken et al., 2015), is related to a range of indicators of physical and mental health (e.g., depression, anxiety), as well as self-efficacy among students (e.g., Bodenlos et al., 2015; Brown \& Ryan, 2003; Murphy et al., 2012). Systematic reviews and meta-analyses have reported an improvement with small to moderate effect sizes in trait mindfulness and mental health through mindfulness-based 
interventions in student samples (e.g., Conley et al., 2015; Halladay et al., 2019; McConville et al., 2016). However, the follow-up outcomes in these meta-analyses have shown heterogeneous results. For example, Halladay et al. (2019) found that significant improvements in depression through mindfulness-based interventions were not maintained at follow-up, whereas significant reductions of anxiety symptoms were sustained at one-month follow-up. However, McConville et al. (2016) found no significant interventions effects on anxiety and mindfulness at follow-up. Further, much less is known about the potential of mindfulness trainings for physical health. In a recent meta-analysis, Spinelli et al. (2019) reported that mindfulness-based interventions had no significant effect on physical health among healthcare professionals and trainees. However, the meta-analysis included only three studies that investigated the effect of mindfulness training on physical health (e.g., heart rate).

In comparison to the positive short-term effects of mindfulness trainings on health and self-efficacy, there have been mixed results obtained from research on the impact of such trainings on other constructs such as cognitive emotion regulation strategies, attention, body awareness, and nonattachment. Cognitive emotion regulation strategies are viewed as mental strategies that individuals use to cope with the intake of emotionally arousing information (e.g., Garnefski et al., 2001). Previous research has classified these strategies into adaptive (e.g., reappraisal) and maladaptive (e.g., rumination) strategies (e.g., Garnefski et al., 2001). Reappraisal is defined as reinterpretation of a stressful situation in a way that modulate one's emotional impact (Hermann et al., 2014), while rumination is defined as the tendency to repetitively focus on one's problems, concerns, and negative emotions (Watkins, 2008). Several studies have shown that rumination is associated with mental health problems (e.g., anxiety, depression) and lower levels of mindfulness, whereas reappraisal is related to lower rates of depression and anxiety and higher levels of mindfulness (e.g., Desrosiers et al., 2014; Hill \& Updegraff, 2012; Burg \& Michalak, 2011). Further, Jain et al. (2007) and Rahl et al. (2017) proposed that mindfulness-based interventions decrease rumination because of the increased practice of moment-to-moment awareness. For reappraisal, Desrosiers et al. (2014) proposed that mindfulness trainings foster the cultivation of a nonjudgmental stance toward experiences. This nonjudgmental stance, in turn, is a form of reframing that can foster a more general tendency toward reappraisal. However, mixed results have been obtained for the effects of mindfulness interventions. For example, Jain et al. (2007) found that participation in a brief mindfulness meditation intervention was associated with a decrease in rumination in a student sample, whereas Haarig et al. (2016) reported no significant effect on university students' rumination.
Similar findings are reported for attention. Although several studies (e.g., Chiesa et al., 2011; Jha et al., 2007) have shown that long-term mindfulness interventions improve attention, the research on the effects of shorter mindfulness trainings on attentional measures is mixed. Some low-dose, brief mindfulness-based intervention studies with healthy adults have shown improvements on attention (e.g., Tang et al., 2007; Zeidan et al., 2010a, b), while others have found no significant effects on attention (e.g., Johnson et al., 2015; Klempel, 2018). Further, there is limited research assessing the effects of mindfulness trainings on body awareness, even though most mindfulness interventions involve exercises that promote body awareness (e.g., body scan, mindful yoga). Body awareness is defined by Price and Mehling (2016) as the ability to notice subtle bodily internal sensations. Previous research has shown that body awareness is important for emotion regulation, mental and physical health, and well-being (e.g., Burzler et al., 2019; Füstös et al., 2013; Herbert et al., 2007). Further, one study found that a long-term mindfulness intervention increased body awareness (Bornemann et al., 2015).

Nonattachment is another construct that has been shown to have beneficial personal and interpersonal effects (e.g., Lamis \& Dvorak, 2014; Sahdra et al., 2016; Shonin \& Van Gordon, 2015; Tran et al., 2014). Sahdra et al. (2015) defined nonattachment as a flexible and balanced way of relating to experiences without suppressing or clinging to such experiences. In other words, nonattachment represents a release from mental fixations. Although it is assumed that nonattachment can be promoted through interventions that include meditation (e.g., mindfulness interventions, Sahdra et al., 2010), little research has been done on this topic. Joss et al. (2020) found that an eight-week Mindfulness-Based Stress Reduction program (MBSR) for young adults with a history of childhood maltreatment significantly increased nonattachment compared to the waitlist control group.

Further, a few meta-analyses and reviews examined the relationship between the number of training hours and effect sizes in treatment outcomes (e.g., Carmody \& Baer, 2009; McConville et al., 2016; Strohmaier, 2020). McConville et al. (2016) reported that both shorter and longer versions of MBSR were effective in reducing anxiety and depression and increasing mindfulness, as well as self-efficacy in student samples. Similarly, in a meta-analysis by Strohmaier (2020), there was no evidence that larger dose mindfulness-based programs were more beneficial than lower dose trainings for psychological outcomes (depression, anxiety, stress). A metaanalysis by Schumer et al. (2018) indicated that the type of mindfulness exercise plays an important role for the effects of low-dose, brief mindfulness trainings. The authors reported that trainings that included multiple mindfulness exercise types had larger reduction effects on emotional distress (e.g., depression, anxiety) than interventions that focused only on 
body scan or breathing. Taken together, there is substantial evidence that lower dose mindfulness trainings with multiple mindfulness exercises are beneficial and also more practical with students' everyday life (Halladay et al., 2019).

Some authors (e.g., Carmody \& Baer, 2008; Kabat-Zinn, 1990) emphasize the importance of home practice of mindfulness exercises to obtain the benefits of participation in a mindfulness training. Carmody and Baer et al. (2008) reported that the extent of home practice of formal meditation exercises (e.g., mindful yoga, body scan) was positively related to changes in psychological symptoms, well-being, and mindfulness in a clinical sample. However, the results of other studies are mixed. Solhaug et al. (2019) found in a student sample a positive relationship between the frequency and duration of formal mindfulness practice and long-term mindfulness, whereas home-based mindfulness practice was not related to coping or mental distress. The results were similar in a study by Jain et al. (2007), who did not find a relationship between home practice of mindfulness exercises and changes in rumination or distraction.

Despite the benefits of mindfulness trainings on mental health, little research, especially on low-dose interventions, has focused on the maintenance of the effects. In addition, very little research has been undertaken to investigate the effects of these interventions on physical health. Furthermore, few studies to date have examined the effects of mindfulness trainings on constructs such as attention, emotional regulation, body awareness and nonattachment, even though most mindfulness-based interventions involve exercises that promote these constructs. Finally, most of the mindfulnessbased intervention studies have not investigated the association between participant compliance (i.e., home practice of mindfulness exercises) and outcomes, and those that did showed mixed results.

Thus, the aims of this study were to investigate (1) whether a low-dose mindfulness-based intervention had short- and middle-term effects on primary (mindfulness, mental and physical health, self-efficacy) and secondary outcomes (attentional control, body awareness, emotion regulation, nonattachment), and (2) whether participant compliance and satisfaction improved the change in primary and secondary outcomes. A 6-week mindfulness-based intervention was compared with a waitlist control group. It was hypothesized that compared to the waitlist group, the mindfulness group show greater improvements in mindfulness, mental and physical health, and self-efficacy from pre- to postintervention and from preintervention to follow-up. Further, it was hypothesized that participation in the mindfulness intervention would lead to greater improvements in emotion regulation, attentional control, body awareness and nonattachment compared to the waitlist group from preintervention to postintervention and from preintervention to follow-up. Third, we explored whether students' compliance (course attendance, mindfulness practice at home) and satisfaction with the mindfulness training would be associated with positive changes in primary and secondary outcomes. Our study is the first low-dose mindfulness intervention study to test for effects on these outcomes in university students.

\section{Method}

\section{Participants}

A total of 71 university students were enrolled in the intervention study at the end of 2018. There were no inclusion criteria other than participants age $(\geq 18)$ and their willingness to take part in this study. They were randomized into a mindfulness group $(n=35)$ and a waitlist control group $(n=36)$. In the intervention group, three participants did not return for postintervention $(\mathrm{n}=32) .13$ students were lost to postintervention in the control group $(n=23)$. At follow-up, 28 participants of the mindfulness group and 22 control participants provided follow-up ratings. The primary reason for dropping out was lack of time. No differences were found between completers and students who dropped out of the study on any baseline measures (described in further detail in the section "Measures" below) [Wilks $\left.\lambda=.841 ; F(9,61)=1.28, p=.26, \eta^{2}=.16\right]$, and on gender $\left[\chi^{2}(1)=.76, p=.38\right]$. The majority of the participants $(80.3 \%)$ were female, and the mean age of the sample was 22.68 years ( $S D=3.26$, age range: $18-35$ years). The average academic semester was $3.94(S D=3.23$, median $=$ 3.00). Participants' demographic characteristics by group are presented in Table 1.

\section{Procedure}

Participants were recruited via university mailing lists and flyers at universities. Data were collected with an online survey immediately before (preintervention, T1) and after the intervention (postintervention, T2), and 2.5 months after the postintervention (follow-up, T3). The online questionnaire itself was preceded by an introductory page to the study, researcher contact information, and confirming voluntary and anonymous participation. Students completed the preintervention

Table 1: Baseline demographic characteristics by group

\begin{tabular}{lrr}
\hline Variable & $\begin{array}{l}\text { Mindfulness } \\
(n=35)\end{array}$ & \multicolumn{1}{c}{$\begin{array}{l}\text { Waitlist } \\
(n=36)\end{array}$} \\
\hline Age, mean $(S D)$ & $22.83(3.07)$ & $22.53(3.46)$ \\
Gender, $n(\%$, female $)$ & $26(76.5)$ & $31(86.1)$ \\
Semester, mean $(S D)$ & $4.54(3.41)$ & $3.36(2.99)$ \\
\hline
\end{tabular}


questionnaire before being randomized to either the mindfulness group or waitlist control group.

\section{Program Description}

The intervention was a 6-week mindfulness training and consisted of one 90-min session (week 1) and five 30-min sessions. The practice of the mindfulness training was derived from the principles of Mindfulness-Based Stress Reduction (MBSR, Kabat-Zinn, 1990; Lehrhaupt \& Meibert, 2011). The intervention was manualized. The trainer manual included a written description of session-by-session content, and a guideline on how to teach the course. The participants met their trainer once a week. The two trainers were members of the research group. The size of the groups was between 11 and 13 participants. Thus, it was a group-based face-to-face mindfulness training. A session typically began with a review and sharing of the home practice from last week. It was then followed by a theoretical introduction to the new mindfulness practices and the participants practiced and discussed this new technique. This low-dose mindfulness training included multiple mindfulness exercise types because of the findings of the meta-analysis by Schumer et al. (2018), as mentioned above. The mindfulness-based exercises included awareness of breathing and body scan meditation (week 1), awareness of breathing and body (week 2), mindful eating (week 3), walking meditation (week 4), sitting meditation (week 5), and mindful hatha yoga (week 6). Participants were encouraged to practice the new mindfulness exercise at home at least once a week. Thus, audio-guided instructions were sent to the participants to carry out their weekly home practice. The trainer recorded the audio-guided instructions for home practice. The intervention was held at the university campus in the late afternoon hours.

Control condition was an inactive (waitlist) group. After the follow-up assessment was completed, individuals in the waitlist control group took part in the mindfulness training. Students in the control group underwent the same data collection schedule as participants in the intervention group.

\section{Measures}

\section{Implementation of the Mindfulness Training}

Student satisfaction with the mindfulness training was measured with four items (e.g., "I was satisfied with... (1) the trainer, (2) the climate of the course, (3) the design of the training course, (4) the conditions of the course (time, room, etc.) .", $\alpha=.62$, Karing $\&$ Beelmann, 2016). Items were rated on a 6-point Likert scale (1 $=$ not at all; $6=$ absolutely). Participant compliance was assessed with course attendance (number of sessions attended) and the frequency of weekly formal mindfulness practice at home (e.g., breath meditation, body scan, yoga). At follow-up, participants' mindfulness practice was assessed. The trainer rated student attention, interest, and cooperation during the sessions on a 6 point Likert scale $(1=$ very bad; $6=$ very good $)$. The extent of the implementation of the manual instructions during the sessions was assessed by trainers themselves after each session (percentage).

\section{Primary Outcome Measures}

Mindfulness was assessed with the Five-Facet Mindfulness Questionnaire (FFMQ; Michalak et al., 2016) consisting of 39 items. The FFMQ measures total dispositional mindfulness and five facets of mindfulness (observe, describe, acting with awareness, nonjudging, nonreactivity; Baer et al., 2006, 2008). The total FFMQ score was used to examine total mindfulness. Items are rated on a 5-point Likert scale $(1=$ never true; 5 = always true) with higher scores indicating higher levels of total mindfulness. Example items included "Even when I'm feeling terribly upset, I can find a way to put it into words" and "I perceive my feelings and emotions without having to react to them." The internal consistency for the scale was $\alpha_{\mathrm{T} 1}=.90, \alpha_{\mathrm{T} 2}=.92$ and $\alpha_{\mathrm{T} 3}=.92$.

Mental health complaints were assessed with a brief screening scale for anxiety and depression (PHQ-4, Löwe et al., 2010). Khubchandani et al. (2016) showed that the PHQ-4 is a reliable and valid screening instrument for depression and anxiety among students. This four-item scale consists of two core criteria for depressive disorders (e.g., "Feeling down, depressed, or hopeless) and two core criteria for generalized anxiety disorder (e.g., "Feeling nervous, anxious, or on edge"; Kroenke et al., 2009). The four response categories ranged from 1 (not at all) to 4 (nearly every day). Higher scores indicated higher levels of mental health complaints. The internal consistency for the scale was $\alpha_{\mathrm{T} 1}=.81, \alpha_{\mathrm{T} 2}=.82$ and $\alpha_{\mathrm{T} 3}=.84$.

Physical health complaints were measured with six items (e.g., headache, back pain, stomach ache, circulatory problems/dizziness, nausea/vomiting, diarrhea/constipation) that were adapted from a scale by Hurrelmann and Kolip (1994). Participants rated items on a 4-point Likert scale ( $1=$ not at all; 4 = frequently). Higher scores reflected higher levels of physical health complaints. Cronbach's $\alpha$ was at $\alpha_{\mathrm{T} 1}=.70$, $\alpha_{\mathrm{T} 2}=.70$ and $\alpha_{\mathrm{T} 3}=.75$ in our sample.

Self-efficacy was assessed using the 10-item general selfefficacy scale (Schwarzer \& Jerusalem, 1999). Participants rated items such as "I can remain calm when facing difficulties because I can rely on my coping abilities." on a 4-point Likert scale ( 1 = not at all true; 4 = exactly true). Higher scores indicate higher levels of self-efficacy. The internal consistency for the scale was $\alpha_{\mathrm{T} 1}=.80, \alpha_{\mathrm{T} 2}=.77$ and $\alpha_{\mathrm{T} 3}=.85$.

\section{Secondary Outcome Measures}

Attentional control was assessed with the 20-item Attentional Control Scale (Derryberry \& Reed, 2002). Items were rated on 
a 4-point Likert scale $(1=$ almost never; $4=$ always $)$. An example item is "My concentration is good even if there is music in the room around me." Higher scores indicate higher levels of attentional control. Cronbach's Alpha was $\alpha_{\mathrm{T} 1}=.83$, $\alpha_{\mathrm{T} 2}=.81$ and $\alpha_{\mathrm{T} 3}=.84$.

Body awareness was measured with the body awareness scale of the Scale of Body Connection (Price \& Thompson, 2007) consisting of 12 items. This scale assesses the ability to experience inner body sensations (i.e., breathing, tension). Participants rated items such as "If there is tension in my body, I am aware of the tension" on a 5-point Likert scale ( $1=$ not at all; $5=$ all of the time). Higher scores indicate higher levels of body awareness. The internal consistency for the scale $\alpha_{\mathrm{T} 1}=$ $.83, \alpha_{\mathrm{T} 2}=.79$ and $\alpha_{\mathrm{T} 3}=.82$

Emotional regulation was measured using two subscales (rumination, reappraisal) from the Heidelberg Form for Emotion Regulation Strategies (HFERST, Izadpanah et al., 2019). Items were rated on a 5 -point Likert scale $(1=$ never; $5=$ always). Higher scores indicating a more frequent use of the strategies. Example items of the two subscales are as follows: rumination (4 items, "I remember past conflicts often and think about what I could have done differently.", $\alpha_{\mathrm{T} 1}=$ $.76, \alpha_{\mathrm{T} 2}=.74$ and $\alpha_{\mathrm{T} 3}=.81$ ) and reappraisal ( 4 items, "When I feel bad, I try to see the positive aspects of a situation.", $\alpha_{\mathrm{T} 1}$ $=.82, \alpha_{\mathrm{T} 2}=.84$ and $\alpha_{\mathrm{T} 3}=.87$ ).

Nonattachment was assessed with the seven-item Nonattachment Scale (Sahdra et al., 2015). Participants rated items such as "When pleasant experiences end, I am fine on moving on to what comes next" on a 6-point Likert scale ( $1=$ disagree strongly; $6=$ agree strongly). Higher scores indicating higher levels of nonattachment. Cronbach's $\alpha$ was at $\alpha_{\mathrm{T} 1}$ $=.72, \alpha_{\mathrm{T} 2}=.78$ and $\alpha_{\mathrm{T} 3}=.76$.

\section{Data Analyses}

Repeated measures analysis (MANOVA, ANOVA) in IBM SPSS Statistics (Version 25) were used to analyze the effects of time, the effects of group and the interaction between time and groups (intervention effect) across the measurement points (T1 and T2, T1 and T3). For all analyses, we conducted Per Protocol (PP) analyses, and Intention-To-Treat (ITT) analyses with missing data accounted for using multiple imputation. ITT analyses include all randomized students in their allocated group. Thus, ITT analyses were conducted on the data from 71 students (mindfulness group: $n=35$, control group: $n=36$ ), whereas PP analyses were performed on the data from 55 students for the short-term effects and on the data from 50 students for the medium-term effects. Further, Pearson's correlations were used to examine whether participant satisfaction with the mindfulness training and participant compliance (course attendance, mindfulness practice at home) improved the change in outcome variables ( $\mathrm{T} 1$ and $\mathrm{T} 2, \mathrm{~T} 1$ and T3). Standardised residualized change scores for the outcome variables were calculated for each time comparison. We used a linear regression model in which preintervention scores predicted postintervention scores or follow-up scores for the outcome variables. Level of significance was set at $p<.05$ (onetailed). Besides partial $\eta^{2}$, Cohen's $d$ was calculated as estimate of effect size because of the disadvantages and difficulty of interpreting partial $\eta^{2}$ (Levine \& Hullett, 2002). According to Cohen's (1988) guidelines, $d=0.20$ can be interpreted as a small effect, $\mathrm{d}=0.50$ is moderate effect, and $\mathrm{d}=0.80$ is a large effect.

\section{Results}

\section{Implementation of the Mindfulness Training}

Students attended a mean of 4.5 sessions $(S D=1.56$, median $=5.00)$ out of 6 . They reported that they were very satisfied with the mindfulness training $(M=5.49, S D=0.43)$. All participants perceived the size of the groups as very appropriate. $91 \%$ of the students would very recommend the mindfulness training to friends and relatives. On average, $64 \%$ of the participants practiced mindfulness at home at least once a week. At follow-up, 79\% of the participants reported that they still practiced mindfulness. Further, the trainer reported that the participants were on average very attentive $(M=5.78, S D$ $=0.27)$, interested $(M=5.39, S D=0.70)$, and cooperative $(M$ $=5.33, S D=0.70$ ) during the sessions. $90 \%$ of the instructions of the manual were implemented by the trainer.

\section{Efficacy of the Mindfulness Training}

\section{Primary Outcomes}

The repeated measures MANOVA using mindfulness, mental and physical complaints, and self-efficacy from pre- to postintervention revealed a significant time effect $[F(4,50)=$ $\left.10.05, p<.001, \eta^{2}=.45\right]$ and a significant time $\mathrm{x}$ group interaction $\left[F(4,50)=3.78, p<.01, \eta^{2}=.23\right]$ in the PP sample. There was no significant group effect $[F(4,50)=$ $\left..43, p=.39, \eta^{2}=.03\right]$. Subsequent repeated measures ANOVAs showed significant interactions between time and group for mindfulness and self-efficacy. As predicted, there was a greater increase over time in mindfulness and selfefficacy in the mindfulness group compared to the control group. Moderate to large effect sizes were observed for these outcomes. However, no significant interaction effects were found for physical and mental health complaints (see Table 2). Multivariate analysis of variance (MANOVA) with repeated measurement was also conducted in the ITT sample. ITT-analysis showed a significant time effect $[F(4,66)=$ $\left.14.69, p<.001, \eta^{2}=.47\right]$. The group effect $[F(4,66)=.21$, $\left.p=.46, \eta^{2}=.01\right]$ and the interaction between time and group 


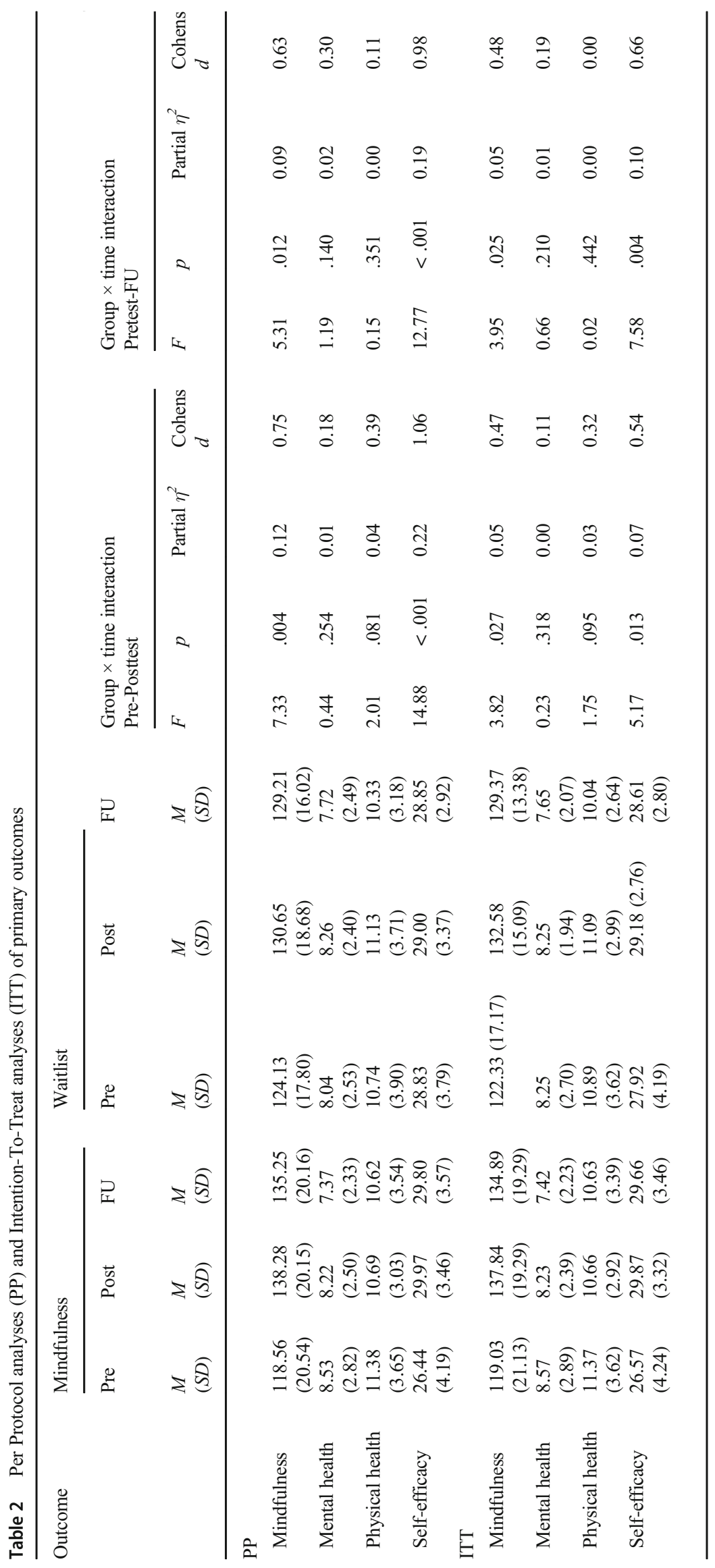


$\left[F(4,66)=1.57, p=.09, \eta^{2}=.09\right]$ were not significant. Detailed analyses of primary results are presented in Table 2.

Both PP and ITT analyses (repeated measures MANOVA) from pre- to follow-up showed a significant time effect [PP: $F(4,50)=5.26, p<.001 ; \eta^{2}=.30$, ITT: $F(4,66)=7.72, p<$ $\left..001 ; \eta^{2}=.32\right]$ and a significant time $\times$ group interaction [PP: $F(4,50)=3.07, p<.05 ; \eta^{2}=.20$, ITT: $F(4,66)=2.13, p<.05$; $\left.\eta^{2}=.11\right]$. There was no effect of group [PP: $F(4,50)=.37, p=$ $.41 ; \eta^{2}=.03$, ITT: $\left.F(4,66)=.28, p=.44 ; \eta^{2}=.02\right]$. Results from both PP and ITT repeated measures ANOVAs showed that the significant intervention effects for mindfulness and self-efficacy were maintained throughout the follow-up. As predicted, there was a steeper increase over time in mindfulness and self-efficacy in the intervention group compared to the control group. Effect sizes were moderate to large for these outcomes. Again, there were no interaction effects for mental and physical health complaints (see Table 2).

\section{Secondary Outcomes}

For secondary outcome results, both PP and ITT repeated measures MANOVA analyses from pre- to postintervention identified a significant time effect [PP: $F(5,49)=6.60, p<$ $.001 ; \eta^{2}=.40$, ITT: $\left.F(5,65)=9.56, p<.001 ; \eta^{2}=.42\right]$ and a significant interaction between time and group [PP: $F(5,49)=$ $2.88, p<.05 ; \eta^{2}=.23$, ITT: $\left.F(5,65)=2.15, p<.05 ; \eta^{2}=.14\right]$. There was no significant group effect [PP: $F(5,49)=.49, p=$ $.39 ; \eta^{2}=.05$, ITT: $\left.F(5,65)=.30, p=.45 ; \eta^{2}=.02\right]$. Subsequent PP and ITT repeated measures ANOVAs showed significant intervention effects for reappraisal and body awareness. Moderate to large effect sizes were found for these outcomes. Although the interaction between time and group for nonattachment was significant in the PP sample, this interaction was not significant in the ITT sample. Moreover, for attentional control and rumination no significant intervention effect was found in both PP and ITT analyses (see Table 3). Similar findings from PP and ITT analyses were found from preintervention to follow-up. The repeated measures MANOVA revealed a significant time effect [PP: $F(5,49)=$ $4.55, p<.01 ; \eta^{2}=32$, ITT: $\left.F(5,65)=4.84, p<.001 ; \eta^{2}=.27\right]$ and a significant interaction between time and group [PP: $F(5$, $49)=2.69, p<.05 ; \eta^{2}=.22$, ITT: $F(5,65)=2.81, p<.05 ; \eta^{2}=$ $.18]$ across the PP and ITT sample. There was no significant group effect [PP: $F(5,49)=.38, p=.43 ; \eta^{2}=.04$, ITT: $F(5$, $\left.65)=.33, p=.44 ; \eta^{2}=.03\right]$. Results from both PP and ITT repeated measures ANOVAs demonstrated that the intervention effects for reappraisal and body awareness were maintained at follow-up. Effect sizes for reappraisal were small to moderate, whereas effect sizes for body awareness were large. Again, the intervention effect for nonattachment was significant in the PP sample, but it was not significant in the ITT sample. No significant group by time interactions were found for attentional control and rumination.

\section{Satisfaction, Compliance and Change in Outcome Variables}

Correlation analyses revealed that greater satisfaction with training was significantly correlated with greater increases in self-efficacy $\left(r_{\mathrm{t} 1-\mathrm{t} 2}=.38, p<.05\right)$ and in body awareness $\left(r_{\mathrm{t} 1-}\right.$ $\left.\mathrm{t} 2^{2}=.41, p<.05, r_{\mathrm{t} 1-\mathrm{t} 3}=.42, p<.05\right)$. Further, greater satisfaction with training was significantly associated with larger decreases in physical health complaints $\left(r_{\mathrm{t} 1-\mathrm{t} 2}=-.38, p<.05\right)$. Moreover, greater frequency of formal mindfulness practice at home was significantly related to a steeper increase in selfefficacy $\left(r_{\mathrm{t} 1-\mathrm{t} 3}=.39, p<.05\right)$. Higher class attendance was associated with larger increases in self-efficacy $\left(r_{\mathrm{t} 1-\mathrm{t} 2}=.30, p\right.$ $\left.<.05, r_{\mathrm{t} 1-\mathrm{t} 3}=.41, p<.01\right)$, mindfulness $\left(r_{\mathrm{t} 1-\mathrm{t} 3}=.34, p<.05\right)$, body awareness $\left(r_{\mathrm{t} 1-\mathrm{t} 3}=.35, p<.05\right)$, and reappraisal $\left(r_{\mathrm{t} 1-\mathrm{t} 2}=\right.$ $.32, p<.05)$.

\section{Discussion}

The present study examined the short- and middle-term effects of a low-dose mindfulness-based training compared to a waitlist control group on primary outcomes (mindfulness, mental and physical health, self-efficacy) and secondary outcomes (emotion regulation, attentional control, body awareness, nonattachment). The first hypothesis was partially supported. The present study found that the mindfulness group showed a greater increase in mindfulness and self-efficacy than the control group, both at postintervention and at follow-up. Moderate effect sizes were observed for mindfulness, and moderate to large effect sizes were found for self-efficacy. A similar finding for a low-dose mindfulness training in a student sample was reported by Yamada and Victor (2012). The authors found that, compared to the control group, the mindfulness group reported an increase in mindfulness from pre- to postintervention. Results by a study from Kiken et al. (2015) suggest that increasing state mindfulness through repeated meditation practice in a mindfulness-based intervention could foster trait mindfulness. Our finding that the training improved self-efficacy is consistent with the result of one earlier study by Phang et al. (2015). The authors demonstrated that a long-term mindfulness-based stress management training in a medical student sample resulted in improvements in self-efficacy over time. The results of the present study provide support that even a low-dose mindfulness training can improve self-efficacy among students. Further, Hosseinzadeh et al. (2019) proposed that mindfulness promotes greater acceptance of one's thoughts and feelings, which in turn will lead to a better sense of self-efficacy. Thus, further research should examine the role of acceptance as a critical component of mindfulness trainings for boosting positive outcomes such as self-efficacy. 


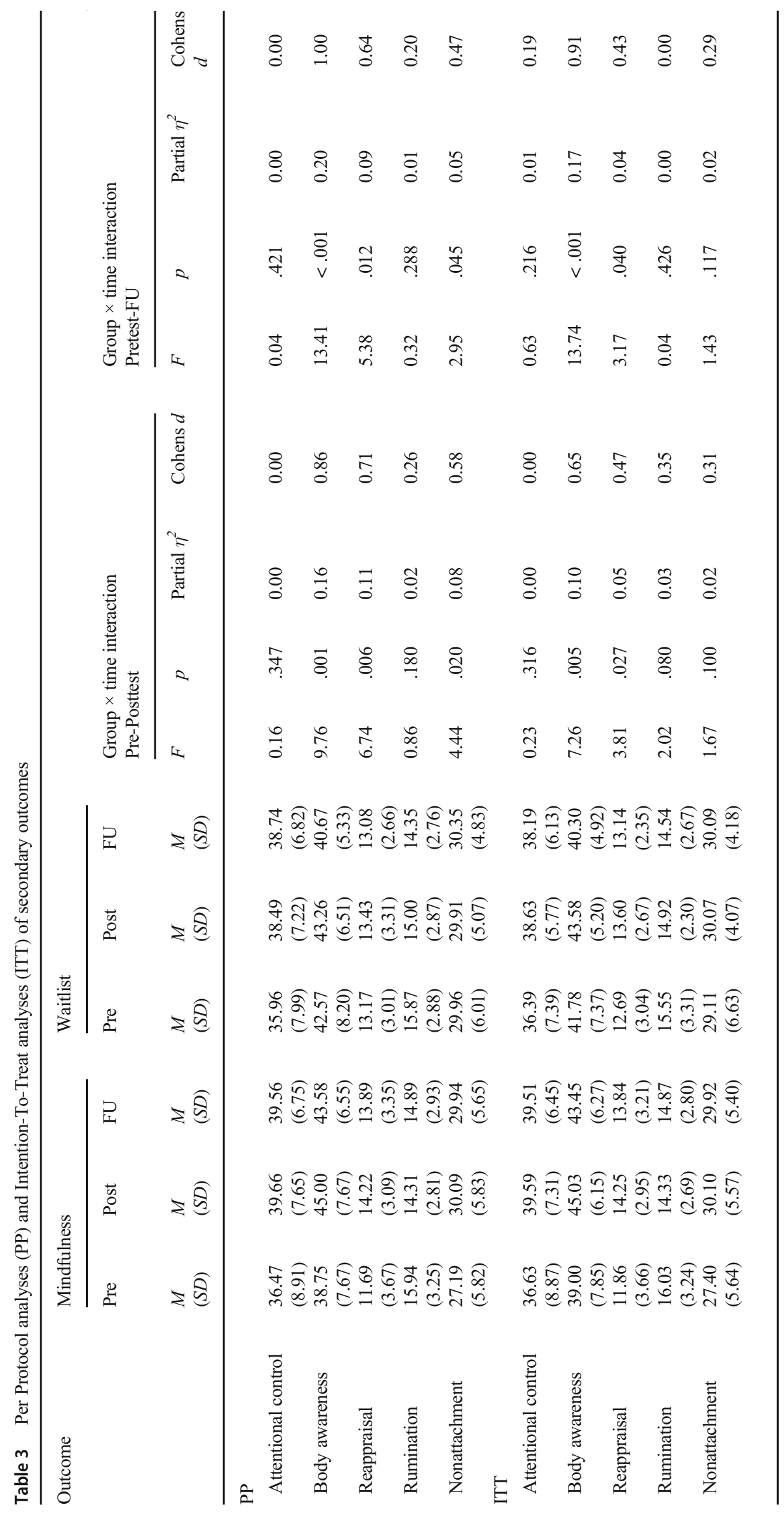


Contrary to our predictions, we did not find an intervention effect on mental and physical health. Our results differ from those of Call et al. (2014) and Tang et al. (2007), who reported that low-dose mindfulness trainings reduced anxiety and depression among students. However, our finding on physical health is in line with the result of Spinelli et al. (2019), who reported in their meta-analysis that mindfulness trainings had no significant effect on physical health. Further, in a metaanalysis, Schumer et al. (2018) found that low-dose, brief mindfulness trainings had larger reduction effects on distress (e.g., depression, anxiety) for community adult populations than for students. The authors concluded that older community adults are likely more adherent and motivated to engage with such trainings than students. In line with this assumption is our finding that greater satisfaction with the mindfulness training was associated with larger decreases in physical complaints. Thus, the implementation quality seems to be important for the effectiveness of low-dose mindfulness trainings. Alternatively, the mean score of mental health complaints (at baseline) in our study reflected moderate depression and anxiety symptoms in both groups (Kroenke et al., 2009). The duration of our sessions or the length of our intervention may have been too short for the reductions of clinically relevant symptoms (i.e., depression, anxiety). A meta-analysis by Chi et al. (2018) found that MBSR reduced depressive symptoms among young people only at postintervention. However, the authors reported that longer interventions had larger effects on the reduction of clinical relevant symptoms than shorter trainings (i.e., less than eight weeks).

The second hypothesis was also only partly confirmed. The study showed a moderate to large intervention effect on body awareness and a small to moderate effect on reappraisal at postintervention and at follow-up. These significant intervention effects hold across ITT and PP analyses. Little research has been done on the effects of mindfulness trainings on body awareness. To our knowledge, our study is the first one that investigated the effect of a low-dose mindfulness training on body awareness in a student sample. Only one study so far examined the effect of a long-term mindfulness training on body awareness and found a positive effect on body awareness (Bornemann et al., 2015). Our findings, as well as the results of Bornemann et al. (2015), are important given that previous studies have shown that body awareness is crucial for regulation of emotions, health, and well-being (e.g., Burzler et al., 2019; Füstös et al., 2013). Thus, mindfulness interventions could strengthen students' use of body sensations to improve their ability to recognize and regulate their emotions, which in turn could lead to better health and wellbeing (e.g., Bornemann et al., 2015).

Extending previous findings to a nonclinical sample and low-dose mindfulness-based interventions, the present study found that the mindfulness group showed a greater increase in reappraisal than the control group, both from pre- to postintervention and from preintervention to follow-up. A similar finding for reappraisal was demonstrated in a clinical sample by Garland et al. (2017). However, the patients participated in a long version of mindfulness-based intervention (MBSR). Further, the authors found that increases in decentering mediated the effect of MBSR on broadening awareness, which in turn mediated increases in reappraisal, as proposed by the Mindfulness to Meaning Theory (Garland et al., 2015). Additional research is needed to examine whether similar mechanisms are found for low-dose mindfulness trainings in nonclinical samples. In contrast, there was no intervention effect on rumination in our study. This finding is in line with the results obtained by Haarig et al. (2016), who found no significant effect of a mindfulness training on rumination among students. In contrast, Jain et al. (2007) reported that a brief mindfulness training in a student sample had a reduction effect on rumination. Notably, the descriptive statistics of our study showed a decrease over time in rumination in the control group. One explanation could be that the control group also used productive strategies to deal with ruminative thoughts.

Although we found a significant intervention effect on nonattachment in the PP sample, this effect was not significant in the ITT sample. However, little research has been conducted on this topic so far. Only one study (Joss et al., 2020) showed that a long version of a mindfulness-based intervention increased nonattachment in a sample of young adults with a history of childhood maltreatment. Thus, some training in mindfulness seems to be necessary to promote nonattachment.

Contrary to our hypothesis, we did not find an intervention effect on attentional control. Prior research on the effects of brief mindfulness-based interventions on attentional control was mixed. Johnson et al. (2015) and Klempel (2018) did not find an effect of brief mindfulness trainings on attention, whereas others (e.g., Tang et al., 2007; Zeidan et al., 2010a, b) found a significant intervention effect. The mixed findings could be due the use of different methods to measure attention and the assessment of attention after or prior to meditation practice. For example, Rani and Rao (2000) found that attention regulation abilities were better immediately after meditation practice. Further, Josefsson and Broberg (2011) argued that it would be more beneficial to use measurements of attention that are more associated with internally directed attention that is practiced in mindfulness meditation.

Finally, the results of the present study showed that the quality of the implementation of the low-dose mindfulness training was important. Greater satisfaction with the training was associated with positive changes in self-efficacy, body awareness, and physical health. These results indicate that mindfulness-based interventions should include various methods (e.g., manuals with modification options, training and supervision for administrator, Beelmann \& Karing, 2014) to reduce implementation problems (e.g., participants' 
satisfaction and cooperation). Moreover, higher class attendance was related to greater increases in mindfulness, selfefficacy, body awareness and reappraisal. Thus, the number of sessions attended seems to be important for the effectiveness of a low-dose mindfulness training. Further, there was only a practice effect on self-efficacy, such that increased formal mindfulness practice at home was associated with steeper increase in self-efficacy. In contrast, Solhaug et al. (2019) found that an MBSR training in students showed a positive effect of formal mindfulness practice on trait mindfulness. Moreover, in a meta-analysis, Parsons et al. (2017) found a positive relationship between the extent of formal home practice and the improvements in psychological and physical outcomes. This corresponds with the Modes of Mind theory of information processing in mindfulness that greater practice of mindfulness should cultivate the shifting from a doing mode of mind into a being mode, therefore reducing mental health problems (Williams, 2008). Future low-dose mindfulness trainings should pay more attention to regular home practice of mindfulness exercises.

\section{Limitations and Future Research Directions}

Limitations of the study need to be considered in interpreting the findings. First, only self-rated outcome measures were used which are subject to response bias. Therefore, future studies should include additional modes of measurement such as objectives and physiological measures. Second, participants were predominantly females. Previous meta-analyses (e.g., Chiesa \& Serretti, 2009; Jayawardene et al., 2017; Regehr et al., 2013) have shown that mindfulness-based intervention studies over-represent interventions with female participants, especially with student samples. However, in a meta-analysis, de Vibe et al. (2017) found no relationship between the magnitude of the effect size for mental health and the percent of female participants in the sample. Third, the absence of an active control group made it impossible to control for nonspecific treatment factors (e.g., support from the administrator, group support). In light of the results of the meta-analysis by Schumer et al. (2018) that low-dose, brief mindfulness trainings had smaller effects on distress when compared to active control groups than to inactive control groups, future studies should include active control groups. For example, future work should include a more comparative control group, such as sham meditation intervention group, which can help to distinguish between the effects of relaxed breathing and the feeling that one is actually meditating (Zeidan et al., 2010a, b). Fourth, future research should include multiple follow-up time points and at longer lengths.

Finally, further studies should examine the mechanisms of change of low-dose mindfulness-based interventions. For example, one could investigate the hypothesis that the effects of the low-dose mindfulness training versus control group on changes in self-efficacy are mediated by changes in acceptance of one's thoughts and feelings as proposed by Hosseinzadeh et al. (2019). Further research on implementation strategies is needed. In particular, future studies should investigate how varying the amount of program sessions attended by participants assigned to low-dose mindfulness training impacts outcome variables (e.g., mindfulness, mental and physical health). Additionally, future studies should address how much formal and informal mindfulness practice at home is necessary in order to promote changes in mindfulness and health.

Authors' Contribution CK designed and executed the study, analyzed the data, and wrote the paper. $\mathrm{AB}$ collaborated in the editing of the final manuscript.

Funding Open Access funding enabled and organized by Projekt DEAL.

\section{Declarations}

Ethical Approval All procedures performed in our study were approved by the institutional review board at the Friedrich-Schiller-University of Jena and in accordance with the ethical standards of the 1964 Helsinki Declaration and its later amendments or comparable ethical standards.

Informed Consent Informed consent was obtained from all participants included in the study.

Conflict of Interest The authors declare no competing interests.

Open Access This article is licensed under a Creative Commons Attribution 4.0 International License, which permits use, sharing, adaptation, distribution and reproduction in any medium or format, as long as you give appropriate credit to the original author(s) and the source, provide a link to the Creative Commons licence, and indicate if changes were made. The images or other third party material in this article are included in the article's Creative Commons licence, unless indicated otherwise in a credit line to the material. If material is not included in the article's Creative Commons licence and your intended use is not permitted by statutory regulation or exceeds the permitted use, you will need to obtain permission directly from the copyright holder. To view a copy of this licence, visit http://creativecommons.org/licenses/by/4.0/.

\section{References}

Baer, R. A., Smith, G. T., Hopkins, J., Krietemeyer, J., \& Toney, L. (2006). Using self-report assessment methods to explore facets of mindfulness. Assessment, 13(1), 27-45. https://doi.org/10.1177/ 1073191105283504

Baer, R. A., Smith, G. T., Lykins, E., Button, D., Krietemeyer, J., Sauer, S., Walsh, E., Duggan, D., \& Williams, J. M. G. (2008). Construct validity of the five facet mindfulness questionnaire in meditating and nonmeditating samples. Assessment, 15(3), 329-342. https://doi. org/10.1177/1073191107313003.

Bai, S., Elavsky, S., Kishida, M., Dvořáková, K., \& Greenberg, M. T. (2020). Effects of mindfulness training on daily stress response in college students: Ecological momentary assessment of a randomized 
controlled trial. Mindfulness, 11, 1433-1445. https://doi.org/10. 1007/s12671-020-01358-x.

Beelmann, A., \& Karing, C. (2014). Implementationsfaktoren undprozesse in der Präventionsforschung: Strategien, Probleme, Ergebnisse, Perspektiven [Implementation factors and processes in prevention research: Strategies, problems, findings, prospects]. Psychologische Rundschau, 65, 129-139. https://doi.org/10.1026/ 0033-3042/a000215.

Bodenlos, J. S., Wells, S. Y., Noonan, M., \& Mayrsohn, A. (2015). Facets of dispositional mindfulness and health among college students. The Journal of Alternative Complementary Medicine, 21, 645-652. https://doi.org/10.1089/acm.2014.0302.

Bornemann, B., Herbert, B. M., Mehling, W. E., \& Singer, T. (2015). Differential changes in self-reported aspects of interoceptive awareness through 3 months of contemplative training. Frontiers in Psychology, 5, Article 1504. https://doi.org/10.3389/fpsyg.2014. 01504.

Brown, K. W., \& Ryan, R. M. (2003). The benefits of being present: Mindfulness and its role in psychological well-being. Journal of Personality and Social Psychology, 84(4), 822-848. https://doi. org/10.1037/0022-3514.84.4.822.

Burg, J. M., \& Michalak, J. (2011). The healthy quality of mindful breathing: associations with rumination and depression. Cognitive Therapy and Research, 35(2), 179-185. https://doi.org/10.1007/ s10608-010-9343-x.

Burzler, M. A., Voracek, M., Hos, M., \& Tran, U. S. (2019). Mechanisms of mindfulness in the general population. Mindfulness, 10, 469-480. https://doi.org/10.1007/s12671-018-0988-y.

Call, D. W., Miron, L. R., \& Orcutt, H. K. (2014). Effectiveness of brief mindfulness techniques in reducing symptoms of anxiety and stress. Mindfulness, 5, 658-668. https://doi.org/10.1007/s12671-0130218-6.

Carmody, J., \& Baer, R. A. (2008). Relationships between mindfulness practice and levels of mindfulness, medical and psychological symptoms and well-being in a mindfulness-based stress reduction program. Journal of Behavioral Medicine, 31(1), 23-33. https://doi. org/10.1007/s10865-007-9130-7.

Carmody, J., \& Baer, R. A. (2009). How long does a mindfulness-based stress reduction program need to be? A brief review of class contact hours and effect sizes for psychological disorders. Journal of Clinical Psychology, 65(6), 627-638. https://doi.org/10.1002/jclp. 20555.

Chi, X., Bo, A., Liu, T., Zhang, P., \& Chi, I. (2018). Effects of mindfulness-based stress reduction on depression in adolescents and young adults: A systematic review and meta-analysis. Frontiers in Psychology, 9, 1034. https://doi.org/10.3389/fpsyg. 2018.01034.

Chiesa, A., \& Serretti, A. (2009). Mindfulness-based stress reduction for stress management in healthy people: A review and meta-analysis. The Journal of Alternative and Complementary Medicine, 15(5), 593-600. https://doi.org/10.1089/acm.2008.0495.

Chiesa, A., Raffaella, C., \& Serretti, A. (2011). Does mindfulness training improve cognitive abilities? A systematic review of neuropsychological findings. Clinical Psychology Review, 31(3), 449-464. https://doi.org/10.1016/j.cpr.2010.11.003.

Cohen, J. (1988). Statistical power analysis for the behavioral sciences (2nd ed.). Hillsdale, NJ: Erlbaum.

Conley, C. S., Durlak, J. A., \& Kirsch, A. C. (2015). A meta-analysis of universal mental health prevention programs for higher education students. Prevention Science, 16(4), 487-507. https://doi.org/10. 1007/s11121-015-0543-1.

de Vibe, M. F., Bjørndal, A., Fattah, S., Dyrdal, G. M., Halland, E., \& Tanner-Smith, E. E. (2017). Mindfulness-based stress reduction (MBSR) for improving health, quality of life and social functioning in adults: A systematic review and meta-analysis. Campbell Systematic Reviews, 13(11). https://doi.org/10.4073/csr.2017.11.
Derryberry, D., \& Reed, M. A. (2002). Anxiety-related attentional biases and their regulation by attentional control. Journal of Abnormal Psychology, 111(2), 225-236. https://doi.org/10.1037//0021-843x. 111.2.225.

Desrosiers, A., Vine, V., Curtiss, J., \& Klemanski, D. H. (2014). Observing nonreactively: A conditional process model linking mindfulness facets, cognitive emotion regulation strategies, and depression and anxiety symptoms. Journal of Affective Disorders, 165, 31-37. https://doi.org/10.1016/j.jad.2014.04.024.

Eissler, C., Walter, S., Sailer, M., \& Jerg-Bretzke, L. (2020). Psychische Gesundheit und Belastung bei Studierenden [Mental health and strain in students]. Prävention und Gesundheitsförderung, 15, 242-249. https://doi.org/10.1007/s11553-019-00746-z.

Füstös, J., Gramann, K., Herbert, B. M., \& Pollatos, O. (2013). On the embodiment of emotion regulation: Interoceptive awareness facilitates reappraisal. Social Cognitive and Affective Neuroscience, 8(8), 911-917. https://doi.org/10.1093/scan/nss089.

Garland, E. L., Farb, N. A., Goldin, P. R., \& Fredrickson, B. L. (2015). The mindfulness-to-meaning theory: Extensions, applications and challenges at the attention-appraisal-emotion interface. Psychological Inquiry, 26(4), 377-387. https://doi.org/10.1080/ 1047840X.2015.1092493.

Garland, E. L., Hanley, A. W., Goldin, P. R., \& Gross, J. J. (2017). Testing the mindfulness-to-meaning theory: Evidence for mindful positive emotion regulation from a reanalysis of longitudinal data. PLoS ONE, 12(12), e0187727. https://doi.org/10.1371/journal. pone. 0187727.

Garnefski, N., Kraaij, V., \& Spinhoven, P. (2001). Negative life events, cognitive emotion regulation and emotional problems. Personality and Individual Differences, 30(8), 1311-1327. https://doi.org/10. 1016/S0191-8869(00)00113-6.

Ghaderi, A. R., \& Rangaiah, B. (2011). Influence of self-efficacy on depression, anxiety and stress among Indian and Iranian students. Journal of Psychosocial Research, 6(2), 231-240. https://doi.org/ 10.12738/estp.2018.3.0128.

Glomb, T. M., Duffy, M. K., Bono, J. E., \& Yang, T. (2011). Mindfulness at work. Research in Personnel and Human Resources Management, 30, 115-157. https://doi.org/10.1108/S07427301(2011)0000030005.

Grobe, T., \& Steinmann, S. (2015). Gesundheitsreport 2015: Gesundheit von Studierenden [Health report: health of students]. https://www. tk.de/centaurus/servlet/contentblob/ 718612/ Datei/4110/ Gesundheitsreport-2015.pdf

Grobe, T. G., Steinmann, S., \& Szecsenyi, J. (2018). Arztreport 2018 [Medical report]. https://www.bar-mer.de/blob/144368/ 08f7b513fdb6f06703c6e9765ee9375f/data/dl-barmer-arztreport2018.pdf

Haarig, F., Winkler, D., Graubner, M., Sipos, L., \& Mühlig, S. (2016). Achtsamkeit zur Stressbewältigung -Ergebnisse einer randomisiertkontrollierten Pilotstudie zu einem Achtsamkeitsorientierten Stressbewältigungstraining (AST) [Mindfulness for stress management - results of a randomized controlled pilot trial of mindfulness stress-reduction-training (MST)]. Zeitschrift für Psychiatrie, Psychologie und Psychotherapie, 64(3), 187-197. https://doi.org/ 10.1024/1661-4747/a000278.

Halladay, J. E., Dawdy, J. L., McNamara, I. F., Chen, A. J., Vitoroulis, I., McInnes, N., \& Munn, C. (2019). Mindfulness for the mental health and well-being of post-secondary students: A systematic review and meta-analysis. Mindfulness, 10(3), 397-414. https://doi.org/10. 1007/s12671-018-0979-z.

Herbert, B. M., Ulbrich, P., \& Schandry, R. (2007). Interoceptive sensitivity and physical effort: Implications for the self-control of physical load in everyday life. Psychophysiology, 44(2), 194-202. https://doi.org/10.1111/j.1469-8986.2007.00493.x.

Hermann, A., Keck, T., \& Stark, R. (2014). Dispositional cognitive reappraisal modulates the neural correlates of fear acquisition and 
extinction. Neurobiology of Learning and Memory, 113, 115-124. https://doi.org/10.1016/j.nlm.2014.03.008.

Hill, C. L. M., \& Updegraff, J. A. (2012). Mindfulness and its relationship to emotional regulation. Emotion, 12(1), 81-90. https://doi.org/10. 1037/a0026355.

Hosseinzadeh, Z., Sayadi, M., \& Orazani, N. (2019). The mediating role of mindfulness in the relationship between self-efficacy and early maladaptive schemas among university students. Current Psychology: A Journal for Diverse Perspectives on Diverse Psychological Issues. Advance online publication. https://doi.org/ 10.1007/s12144-019-00487-4.

Hurrelmann, K., \& Kolip, P. (1994). Der Jugendgesundheitssurvey [The youth health survey]. Pressedienst, SFB 227, Nr. 11

Izadpanah, S., Barnow, S., Neubauer, A. B., \& Holl, J. (2019). Development and validation of the Heidelberg Form for Emotion Regulation Strategies (HFERST): Factor structure, reliability, and validity. Assessment, 26(5), 880-906. https://doi.org/10.1177/ 1073191117720283.

Jain, S., Shapiro, S. L., Swanick, S., Roesch, S. C., Mills, P. J., Bell, I., \& Schwartz, G. E. (2007). A randomized controlled trial of mindfulness meditation vs. relaxation training: Effects on distress, positive states of mind, rumination and distraction. Annals of Behavioral Medicine, 33(1), 11-21. https://doi.org/10.1207/ s15324796abm3301_2.

Jayawardene, W. P., Lohrmann, D. K., Erbe, R. G., \& Torabi, M. R. (2017). Effects of preventive online mindfulness interventions on stress and mindfulness: A meta-analysis of randomized controlled trials. Preventive Medicine Reports, 5, 150-159. https://doi.org/10. 1016/j.pmedr.2016.11.013.

Jha, A. P., Krompinger, J., \& Baime, M. J. (2007). Mindfulness training modifies subsystems of attention. Cognitive, Affective, \& Behavioral Neuroscience, 7(2), 109-119. https://doi.org/10.3758/cabn.7.2.109.

Johnson, S., Gur, R. M., David, Z., \& Currier, E. (2015). One-session mindfulness meditation: A randomized controlled study of effects on cognition and mood. Mindfulness, 6, 88-98. https://doi.org/10. 1007/s12671-013-0234-6.

Josefsson, T., \& Broberg, A. (2011). Meditators and non-meditators on sustained and executive attentional performance. Mental Health, Religion \& Culture, 14(3), 291-309. https://doi.org/10.1080/ 13674670903578621.

Joss, D., Lazar, S. W., \& Teicher, M. H. (2020). Nonattachment predicts empathy, rejection sensitivity, and symptom reduction after a mindfulness-based intervention among young adults with a history of childhood maltreatment. Mindfulness. Advance online publication. https://doi.org/10.1007/s12671-020-01322-9.

Kabat-Zinn, J. (1990). Full catastrophe living: Using the wisdom of your body and mind to face stress, pain, and illness. Dell.

Kabat-Zinn, J. (2003). Mindfulness-based interventions in context: Past, present, and future. Clinical Psychology: Science and Practice, 10(2), 144-156. https://doi.org/10.1093/clipsy.bpg016.

Karing, C., \& Beelmann, A. (2016). Implementation und Evaluation eines multimodalen Stressbewältigungstrainings bei Lehramtsstudierenden [Implementation and evaluation of a stress prevention program with teacher students]. Zeitschrift für Gesundheitspsychologie, 24(2), 89-101. https://doi.org/10.1026/ 0943-8149/a000159.

Khubchandani, J., Brey, R., Kotecki, J., Kleinfelder, J., \& Anderson, J. (2016). The psychometric properties of PHQ-4 Depression and Anxiety screening scale among college students. Archives of Psychiatric Nursing, 30(4), 457-462. https://doi.org/10.1016/j. apnu.2016.01.014.

Kiken, L. G., Garland, E. L., Bluth, K., Palsson, O. S., \& Gaylord, S. A. (2015). From a state to a trait: Trajectories of state mindfulness in meditation during intervention predict changes in trait mindfulness. Personality and Individual Differences, 81, 41-46. https://doi.org/ 10.1016/j.paid.2014.12.004.
Klempel, N. M. (2018). The effect of brief mindfulness meditation in training on attention, affect, and mindfulness skills. Hampstead: Hofstra University.

Kroenke, K., Spitzer, R. L., Williams, J. B. W., \& Löwe, B. (2009). An ultra-brief screening scale for anxiety and depression: the PHQ-4. Psychosomatics, 50(6), 613-662. https://doi.org/10.1176/appi.psy. 50.6.613.

Lamis, D. A., \& Dvorak, R. D. (2014). Mindfulness, nonattachment, and suicide rumination in college students: The mediating role of depressive symptoms. Mindfulness, 5, 487-496. https://doi.org/10.1007/ s12671-013-0203-0.

Lehrhaupt, L., \& Meibert, P. (2011). Stress bewältigen mit Achtsamkeit: $\mathrm{Zu}$ inneren Ruhe kommen durch MBSR [Mindfulness-based stress reduction]. Kösel-Verlag.

Levine, T. R., \& Hullett, C. R. (2002). Eta squared, partial eta squared, and misreporting of effect size in communication research. Human Communication Research, 28(4), 612-625. https://doi.org/10.1111/ j.1468-2958.2002.tb00828.x.

Litmanen, T., Loyens, S. M. M., Sjöblom, K., \& Lonka, K. (2014). Medical students' perceptions of their learning environment, wellbeing and academic self-concept. Creative Education, 5, 18561868. https://doi.org/10.4236/ce.2014.521207.

Löwe, B., Wahl, I., Rose, M., Spitzer, C., Glaesmer, H., Wingenfeld, K., Schneider, A., \& Brähler, E. A. (2010). A 4 item measure of depression and anxiety. Journal of Affective Disorders, 122(1-2), 86-95. https://doi.org/10.1016/j.jad.2009.06.019.

McConville, J., McAleer, R., \& Hahne, A. (2016). Mindfulness training for health profession students - The effect of mindfulness training on psychological well-being, learning and clinical performance of health professional students: A systematic review of randomized and non-randomized controlled trials. EXPLORE: The Journal of Science \& Healing, 13(1), 26-45. https://doi.org/10.1016/j. explore.2016.10.002.

Michalak, J., Zarbock, G., Drews, M., Otto, D., Mertens, D., Ströhle, G., Schwinger, M., Dahme, B., \& Heidenreich, T. (2016). Erfassung von Achtsamkeit mit der deutschen Version des Five Facet Mindfulness Questionnaires (FFMQ-D) [Assessment of mindfulness with the German version of the Five Facet Mindfulness Questionnaires (FFMQ-D)]. Zeitschrift für Gesundheitspsychologie, 24(1), 1-12. https://doi.org/10.1026/ 0943-8149/a000149.

Murphy, M. J., Mermelstein, L. C., Edwards, K. M., \& Gidycz, C. A. (2012). The benefits of dispositional mindfulness in physical health: A longitudinal study of female college students. Journal of American College Health, 60(5), 341-348. https://doi.org/10.1080/ 07448481.2011 .629260 .

Parsons, C. E., Crane, C., Parsons, L. J., Fjorback, L. O., \& Kuyken, W. (2017). Home practice in mindfulness-based cognitive therapy and mindfulness-based stress reduction: A systematic review and metaanalysis of participants' mindfulness practice and its association with outcomes. Behaviour Research and Therapy, 95, 29-41. https://doi. org/10.1016/j.brat.2017.05.004.

Phang, C. K., Mukhtar, F., Ibrahim, N., Keng, S. L., \& Sidik, S. M. (2015). Effects of a brief mindfulness-based intervention program for stress management among medical students: The Mindful-Gym randomized controlled study. Advances in Health Sciences Education, 20(5), 1115-1134. https://doi.org/10.1007/s10459-0159591-3.

Price, C., \& Mehling, W. (2016). Body awareness and pain. In D. Thompson \& M. Brooks (Eds.), Integrative Pain Management (pp. 235-251). HandSpring.

Price, C., \& Thompson, E. A. (2007). Measuring dimensions of body connection: Body awareness and bodily dissociation. The Journal of Alternative and Complementary Medicine, 13(9), 945-954. https://doi.org/10.1089/acm.2007.0537. 
Rahl, H. A., Lindsay, E. K., Pacilio, L. E., Brown, K. W., \& Creswell, J. D. (2017). Brief mindfulness meditation training reduces mind wandering: The critical role of acceptance training. Emotion, 17(2), 224 230. https://doi.org/10.1037/emo0000250.

Rani, N. J., \& Rao, P. V. K. (2000). Effects of meditation on attention processes. Journal of Indian Psychology, 18(1-2), 52-60.

Regehr, C., Glancy, D., \& Pitts, A. (2013). Interventions to reduce stress in university students: A review and meta-analysis. Journal of Affective Disorders, 148(1), 1-11. https://doi.org/10.1016/j.jad. 2012.11.026.

Sahdra, B., Shaver, P., \& Brown, K. (2010). A scale to measure nonattachment: A Buddhist complement to western research on attachment and adaptive functioning. Journal of Personality Assessment, 92(2), 116-127. https://doi.org/10.1080/00223890903425960.

Sahdra, B. K., Ciarrochi, J., Parker, P. D., Marshall, S., \& Heaven, P. (2015). Empathy and nonattachment independently predict peer nominations of prosocial behavior of adolescents. Frontiers in Psychology, 6(263), 1-12. https://doi.org/10.3389/fpsyg.2015. 00263.

Sahdra, B., Ciarrochi, J., \& Parker, P. (2016). Nonattachment and mindfulness: Related but distinct constructs. Psychological Assessment, 28(7), 819-829. https://doi.org/10.1037/pas0000264.

Schumer, M. C., Lindsay, E. K., \& Creswell, J. D. (2018). Brief mindfulness training for negative affectivity: A systematic review and meta-analysis. Journal of Consulting and Clinical Psychology, 86(7), 569-583. https://doi.org/10.1037/ccp0000324.

Schwarzer, R., \& Jerusalem, M. (1999). Skalen zur Erfassung von Lehrer- und Schülermerkmalen [Scales to measure characteristics of students and teachers]. Berlin: Freie Universität Berlin.

Shonin, E., \& Van Gordon, W. (2015). Managers' experiences of meditation awareness training. Mindfulness, 6, 899-909. https://doi.org/ 10.1007/s.12671-014-0334-y.

Solhaug, I., de Vibe, M., Friborg, O., Sørlie, T., Tyssen, R., Bjørndal, A., \& Rosenvinge, J. H. (2019). Long-term mental health effects of mindfulness training: a 4-year follow-up study. Mindfulness, 10, 1661-1672. https://doi.org/10.1007/s12671-019-01100-2.

Spinelli, C., Wisener, M., \& Khoury, B. (2019). Mindfulness training for healthcare professionals and trainees: A meta-analysis of randomized controlled trials. Journal of Psychosomatic Research, 120, 2938. https://doi.org/10.1016/j.psychores.2019.03.003.
Stallman, H. M. (2010). Psychological distress in university students: A comparison with general population data. Australian Psychologist, 45, 249-257. https://doi.org/10.1080/00050067.2010.482109.

Strohmaier, S. (2020). The Relationship between doses of mindfulnessbased programs and depression, anxiety, stress, and mindfulness: a dose-response meta-regression of randomized controlled trials. Mindfulness, 11, 1315-1335. https://doi.org/10.1007/s12671-02001319-4.

Tang, Y. Y., Ma, Y., Wang, J., Fan, Y., Feng, S., Lu, Q., Yu, Q., Sui, D., Rothbart, M. K., Fan, M., \& Posner, M. I. (2007). Short-term meditation training improves attention and self-regulation. Proceedings of the National Academy of Sciences of the United States of America, 104(43), 17152-17156. https://doi.org/10.1073/pnas. 0707678104.

Tran, U. S., Cebolla, A., Glück, T. M., Soler, J., Garcia-Campayo, J., \& Von Moy, T. (2014). The serenity of the meditating mind: A cross-cultural psychometric study on a two-factor higher order structure of mindfulness, its effects, and mechanisms related to mental health among experienced meditators. PLoS One, 9(10), 1-13. https://doi.org/10.1371/journal.pone.0110192.

Watkins, E. R. (2008). The constructive and unconstructive consequences of repetitive thought. Psychological Bulletin, 134(2), 163-206. https://doi.org/10.1037/0033-2909.134.2.163.

Williams, J. M. G. (2008). Mindfulness, depression and modes of mind. Cognitive Therapy and Research, 32, 721-733. https://doi.org/10. 1007/s10608-008-9204-z.

Yamada, K., \& Victor, T. L. (2012). The impact of mindful awareness practices on college student health, well-being, and capacity for learning. Psychology Learning \& Teaching, 11(2), 139-145. https://doi.org/10.2304/plat.2012.11.2.139.

Zeidan, F., Johnson, S., Diamond, B., David, Z. H., \& Goolkasian, P. (2010a). Mindfulness meditation improves cognition: Evidence of brief mental training. Consciousness and Cognition, 19(2), 597605. https://doi.org/10.1016/j.concog.2010.03.014.

Zeidan, F., Johnson, S., Gordon, N., \& Goolkasian, P. (2010b). Effects of brief and sham mindfulness meditation on mood and cardiovascular variables. The Journal of Alternative and Complementary Medicine, 16(8), 1-7. https://doi.org/10.1089/acm.2009.0321.

Publisher's Note Springer Nature remains neutral with regard to jurisdictional claims in published maps and institutional affiliations. 